THE INTRINSIC VALUE OF DECISION RIGHTS

Author(s): Björn Bartling, Ernst Fehr and Holger Herz

Source: Econometrica, Vol. 82, No. 6 (November 2014), pp. 2005-2039

Published by: The Econometric Society

Stable URL: http://www.jstor.org/stable/43616906

Accessed: 19-02-2018 11:04 UTC

JSTOR is a not-for-profit service that helps scholars, researchers, and students discover, use, and build upon a wide range of content in a trusted digital archive. We use information technology and tools to increase productivity and facilitate new forms of scholarship. For more information about JSTOR, please contact support@jstor.org.

Your use of the JSTOR archive indicates your acceptance of the Terms \& Conditions of Use, available at http://about.jstor.org/terms 


\title{
THE INTRINSIC VALUE OF DECISION RIGHTS
}

\author{
BY BJÖRN BARTLING, ERNST FEHR, AND HOLGER HERZ ${ }^{1}$
}

\begin{abstract}
Philosophers, psychologists, and economists have long argued that certain decision rights carry not only instrumental value but may also be valuable for their own sake. The ideas of autonomy, freedom, and liberty derive their intuitive appeal-at least partly-from an assumed positive intrinsic value of decision rights. Providing clean evidence for the existence of this intrinsic value and measuring its size, however, is intricate. Here, we develop a method capable of achieving these goals. The data reveal that the large majority of our subjects intrinsically value decision rights beyond their instrumental benefit. The intrinsic valuation of decision rights has potentially important consequences for corporate governance, human resource management, and optimal job design: it may explain why managers value power, why employees appreciate jobs with task discretion, why individuals sort into self-employment, and why the reallocation of decision rights is often very difficult and cumbersome. Our method and results may also prove useful in developing an empirical revealed preference foundation for concepts such as "freedom of choice" and "individual autonomy."
\end{abstract}

KEYWORDS: Decision rights, authority, private benefits of control.

\section{INTRODUCTION}

THE OPTIMAL ALLOCATION OF DECISION RIGHTS is important for achieving efficient outcomes in organizations, markets, and society at large. In economics, the incomplete contracting literature led to an extensive analysis of institutions and organizations in terms of concepts like control rights, decision-making rules, or authority (e.g., Simon (1951), Grossman and Hart (1986), Hart and Moore (1990), Aghion and Tirole (1997), Dessein (2002), Bartling, Fehr, and Schmidt (2013)). A common feature in these models is that decision rights are viewed as purely instrumental for achieving certain outcomes. In this paper, we examine whether decision rights are only a means to an end or whether they carry an intrinsic value beyond their instrumental value of providing the power to enforce preferred outcomes. ${ }^{2}$

\footnotetext{
${ }^{1}$ The Walras-Bowley Lecture that Ernst Fehr presented at the North American Summer Meeting of the Econometric Society at Northwestern University, Evanston, in June 2012 was based on the content of this paper. We would like to thank our referees and the editor for very valuable and helpful guidance. We are also grateful to Alain Cohn, Charles Efferson, Jon Elster, Bob Gibbons, Herb Gintis, Oliver Hart, Michael Kosfeld, Rafael Lalive, Igor Letina, Nick Netzer, Bastiaan Oud, Michael Powell, Clemens Puppe, Klaus M. Schmidt, Andrei Shleifer, Eric van den Steen, Roberto Weber, Tom Wilkening, Christian Zehnder, and Florian Zimmermann, as well as seminar participants at Aarhus, British Columbia, Frankfurt, Harvard, Lausanne, MIT, Northwestern, Rotterdam, Royal Holloway, and Zurich for helpful comments and suggestions.

${ }^{2}$ The idea that decision rights are intrinsically valued already found a particular manifestation in Adam Smith's lectures on jurisprudence delivered at the University of Glasgow in 1762/63. He argued that slavery will never be abolished in a democracy of slave holders because "the love of domination and authority and the pleasure men take in having every[thing] done by their express
} 
Why would individuals value decision rights beyond their instrumental benefits? Social psychologists argue that human needs constitute a source of the intrinsic value of power and autonomy. Power is a dominant human need in McClelland's (1975) motivation theory, and the self-determination theory by Deci and Ryan (1985) hypothesizes that autonomy is "essential for ongoing psychological growth, integrity, and well-being" (Deci and Ryan (2000, p. 229)). Similarly, Frey, Benz, and Stutzer (2004) argued that independence and autonomy at the workplace are sources of procedural utility that raise happiness. In economic philosophy, the capabilities approach by Sen and Nussbaum (e.g., Sen (1985), Nussbaum (2000)) advances a related argument. They emphasized that not only outcomes, but also the freedom of choice, are important for a person's quality of life: "The central capabilities are not just instrumental for further pursuits: they are held to have value in themselves, in making the life that includes them fully human" (Nussbaum (2000, p. 74)). Finally, in moral and political philosophy, John Stuart Mill argued that liberty is "one of the elements of wellbeing" (1859, Chapter III), and individual autonomy is regarded as a basic moral and political value (see, e.g., Christman (2011)).

The difficulty in assessing whether individuals value decision rights intrinsically arises from the necessity to separate the intrinsic value from the instrumental value. We designed an experiment that achieves this separation on the basis of subjects' revealed preferences. Our experiment consists of two parts. In Part 1, we implement a delegation game in which a principal (she) can keep her decision right or delegate it to an agent (him). If the principal keeps the decision right, she can unilaterally determine (i) which of two available project alternatives to implement and (ii) how much costly effort she wants to spend to implement the chosen project successfully. If the principal delegates the decision right, the agent can unilaterally determine the choices in (i) and (ii). The principal faces a trade-off when she decides whether to delegate the decision right. On the one hand, the party who holds the decision right has to bear the cost of implementation effort. On the other hand, the party can also choose the project alternative, and one project leads to a higher expected payoff for the principal, while the other project leads to a higher expected payoff for the agent. The effort determines the probability of success for the chosen project. The choices of the party holding the decision right therefore induce a lottery over monetary payments for both the principal and the agent.

The key innovation in Part 1 of our experiment consists of implementing an incentive compatible method that elicits the principal's point of indifference between keeping and delegating the decision right. To this end, the principal has to choose a minimum requirement for the agent's implementation

orders, rather than to condescend to bargain and treat with those whom they look upon as their inferiors and are inclined to use in a haughty way; this love of domination and tyrannizing, I say, will make it impossible for slaves in a free country ever to recover their liberty" (Smith (1978, p. 186)). We owe this reference to Jon Elster. 
effort. Without knowing the principal's minimum requirement, the agent privately chooses a binding effort level, which is implemented if delegation actually takes place. If the agent's effort is above or equal to the minimum requirement, delegation takes place. If the agent's effort is strictly below the minimum requirement, the decision right remains with the principal. Thus, the minimum requirement does not restrain the agent's effort choice in any way. It only determines, jointly with the agent's effort choice, whether delegation takes place. By determining a minimal effort requirement, the principal can keep the decision right whenever the agent's actual effort choice would make her worse off and delegate the right otherwise. The mechanism ensures that it is optimal for the principal to set the minimum effort requirement in such a way that if the agent were to choose exactly the minimum requirement, the principal is just indifferent between keeping and delegating the decision right.

The principal's own effort and project choices define a "control lottery," and the minimum effort requirement together with the project alternative that gives the higher expected monetary payoff to the agent defines a "delegation lottery." Note that the principal's utility when keeping control consists of the monetary value of the control lottery plus a possible intrinsic utility component associated with being in control that reflects the intrinsic value of the decision right. If, instead, delegation takes place and the minimum effort requirement is chosen, the principal's utility consists of the monetary value of the delegation lottery. Consequently, at the elicited point of indifference, the following equality holds:

\section{monetary value of the control lottery + intrinsic value of decision right}

$=$ monetary value of the delegation lottery.

We measure the monetary values of the delegation and control lotteries in Part 2 of the experiment by eliciting the principal's certainty equivalents of the delegation and control lotteries. Importantly, this value elicitation takes place outside the context of the delegation game. In Part 2, the principals are confronted with the lotteries their decisions in the delegation game generated, but these lotteries are now given exogenously, meaning that the intrinsic value component is absent. It follows that if the certainty equivalent of the control lottery is smaller than the certainty equivalent of the delegation lottery, then the principal must place a positive intrinsic value on the decision right. In other words, the principal is willing to pay a "control premium" if she intrinsically values the decision right, and this control premium can be measured by the difference between the certainty equivalent of the delegation lottery and the certainty equivalent of the control lottery.

Our main finding is that principals indeed assign significantly larger certainty equivalents to the delegation lotteries than to the control lotteries in Part 2. Each principal played the delegation game 10 times, using 10 different parameterizations, and on average, the principals value the delegation lotteries 16.7 
percent more than the control lotteries. At the individual level, the data show that the large majority of the principals assign a positive intrinsic value to decision rights. Moreover, our result is found consistently across the ten different parameterizations. We also find that the individual intrinsic valuations are correlated across the different parameterizations, suggesting that it is rooted in a relatively stable individual preference.

We do not want to argue in this paper that decision rights are always intrinsically valuable, and we expect situational determinants to affect this value crucially. For example, if decision rights involve the choice between fair and unfair outcomes, some people might prefer not making these decisions (Bartling and Fischbacher (2012)). We address two potential situational determinants by systematically varying (i) the stake size of the decisions and (ii) the conflict of interest between the principal and the agent with regard to the project alternative in the ten rounds in Part 1 . With regard to stake size, we find that the intrinsic value of decision rights is not just a fixed amount, but that it increases roughly in proportion to the payoffs under consideration. With regard to conflict of interest, we find that the intrinsic value of decision rights is lower if the principal's conflict of interest with the agent is higher. This finding suggests that, while the instrumental value of decision rights is clearly higher if conflicts of interest are higher, having control in situations with a payoff conflict is less intrinsically valuable.

Our experimental results contribute to the corporate finance and governance literatures, where non-contractible private benefits of control are at the center of the debate (e.g., Aghion and Bolton (1992)). While private benefits are often interpreted as being material in nature, such as the tangible perquisites top executives enjoy (Jensen and Meckling (1976)), the literature also refers to "private benefits of control as the 'psychic' value some shareholders attribute simply to being in control" (Dyck and Zingales (2004, p. 540)). Similarly, to motivate private benefits of control, Hart and Moore (1995) claimed that "among other things, managers have goals, such as the pursuit of power" (p. 568). However, the measurement of psychic benefits of control has escaped precise measurement until now. Our experimental study provides evidence for the relevance of private benefits of control and the theoretical literature that evolved around them. ${ }^{3}$ The relevance of this source of utility has also been discussed in the entrepreneurship literature. Hamilton (2000) showed that entrepreneurs effectively forego earnings for their self-employment; the same has also been suggested for scientists (see Stern (2004)). Pugsley and

\footnotetext{
${ }^{3}$ Anecdotal evidence suggests that the intrinsic value of decision rights might even inhibit mergers due to disputes over the allocation of decision rights in the merged company. For example, the planned merger between Glaxo-Wellcome and SmithKline Beecham in 1998, which would have been the largest merger ever at that time, failed because the top executives of the merging firms were unable to agree on the division of decision rights in the merged entity. This case of merger failure was also described as a "clash of egos" (Morrow (1998)). The firms finally merged two years later, after the retirement of the SmithKline Beecham CEO.
} 
Hurst (2011) documented that non-pecuniary motives are a major driver of the decision to enter self-employment, and Moskowitz and Vissing-Jørgensen (2002) argued that the corresponding wage differentials may be as large as $143 \%$ of total annual income.

Our findings are also related to the literature on incomplete contracts and the delegation of authority (e.g., Aghion and Tirole (1997)). Non-contractible intrinsic benefits of control are likely to bias principals towards keeping decision rights, possibly to the detriment of other parties within the organization and of organizational efficiency. ${ }^{4}$ For example, Fehr, Herz, and Wilkening (2013) found significant underdelegation of decision rights from principals to agents in experimentally controlled situations in which delegation would clearly be preferable for both parties in terms of expected monetary payoffs. Similarly, Owens, Grossman, and Fackler (2014) found that individuals are willing to sacrifice expected earnings to retain control. ${ }^{5}$ Falk and Kosfeld (2006) provided a related experimental finding by showing that limiting agents' choice sets can reduce positive reciprocity. However, none of these papers identifies the intrinsic value of decision rights. In Fehr, Herz, and Wilkening (2013) as well as in Owens, Grossman, and Fackler (2014), the authors cannot rule out that the reluctance to delegate is driven by other factors such as regret or ambiguity aversion because of the uncertainty about the agents' choices after delegation. ${ }^{6}$

Finally, our findings have a bearing on the implications of high-performance work systems (HPWS) (Ichniowsky, Shaw, and Prennushi (1997), Ichniowsky and Shaw (2003), Bartling, Fehr, and Schmidt (2012)). The literature on HPWS argues that certain job characteristics such as workers' decision rights and the payment of high wages emerge jointly because employees are required to contribute more ideas and effort under HPWS than under traditional systems; paying higher wages is a way to induce this contribution (Osterman (2006)). The empirical results on the correlation between HPWS and higher wage levels are mixed, however (e.g., Handel and Levine (2004), Osterman (2006)). This could be due to the fact that the provision of decision rights to workers raises their utility and thus reduces the necessity to compensate them with higher wages. The intrinsic value of decision rights might thus explain the missing link between HPWS and wage levels.

\footnotetext{
${ }^{4}$ Following this logic, models of empire-building (Niskanen (1971)) may be partly founded on an intrinsic value of decision rights.

${ }^{5}$ Somewhat relatedly, Dominguez-Martinez, Sloof, and von Siemens (2014) studied the use of strategic ignorance in the delegation of real authority within a firm. They found that managers show a tendency towards control that seems to be driven by loss aversion. However, they did not provide a measurement of the intrinsic value of decision rights.

${ }^{6}$ These authors acknowledged this fact. Fehr, Herz, and Wilkening attributed the reluctance to delegate explicitly to the principals' regret aversion, while Owens, Grossmann, and Fackler mentioned that ambiguity aversion may "contribute and partially explain the existence of a control premium" in their data.
} 
Finally, we believe that our results may be of value for the debate on the intrinsic value of "liberty" or the "freedom to choose" (e.g., Mill (1859), Sen (1985), Puppe (1996), Nussbaum (2000)). It is intuitively appealing to assume that "freedom of choice" is intrinsically valuable, but we are not aware of the existence of a preference based empirical foundation of the concept. There seems to be no precise empirical method that substantiates that individuals value the freedom to choose beyond the instrumental benefits that this freedom provides. Perhaps our method and findings may help develop such an empirical foundation.

The remainder of the paper is organized as follows. Section 2 outlines the experimental design for measuring the intrinsic value of decision rights in detail. Section 3 presents the theoretical framework behind our experimental design. Section 4 reports the experimental results. Section 5 discusses potential alternative explanations of our results. Section 6 concludes.

\section{EXPERIMENTAL DESIGN}

Our elicitation method is designed to measure a principal's intrinsic value of decision rights, while controlling for her preferences over monetary outcomes as well as for her beliefs about the agent's choices after delegation. We first collect the principals' choices in a delegation game, and later elicit their evaluations of the monetary consequences of these choices in a lottery task with exogenously given lotteries.

\subsection{Part 1: The Delegation Game}

In Part 1 of the experiment, we implement a one-shot delegation game, in which a principal is matched with an agent. Initially, the principal holds the decision right, which grants the right to implement a project, whose outcome determines the principal's and the agent's payoffs. The implementation of a project involves making two decisions: the choice between two possible project alternatives and the determination of the probability of success of the project. In total, the subjects participate in ten different delegation games ("rounds") with perfect stranger matching.

\subsubsection{The Choice of the Project Alternative}

A project can be implemented in one of two alternatives: alternative $\mathcal{P}$ or alternative $\mathcal{A}$. The successful implementation of the project generates a private monetary payoff that depends on the chosen alternative. The monetary payoffs for the principal and the agent are denoted by $P$ and $A$, respectively, and the specific monetary payoffs that result from alternatives $\mathcal{P}$ and $\mathcal{A}$ are given by $P_{\mathcal{P}}$ or $P_{\mathcal{A}}$ for the principal and by $A_{\mathcal{P}}$ or $A_{\mathcal{A}}$ for the agent. If the project implementation is not successful, the principal and the agent receive outside payoffs of $P_{0}$ and $A_{0}$, respectively. The principal weakly prefers alternative $\mathcal{P}$ 
over alternative $\mathcal{A}$, and the agent weakly prefers alternative $\mathcal{A}$ over alternative $\mathcal{P}$. Independent of the alternative, a successful implementation is always preferred to an unsuccessful implementation. We thus have $P_{\mathcal{P}} \geq P_{\mathcal{A}}>P_{0}$ and $A_{\mathcal{A}} \geq A_{\mathcal{P}}>A_{0}$. The exact project payoffs differ across rounds of Part 1 of the experiment, but they are always common knowledge. Before principal and agent know who will ultimately hold the decision right in a given round, both indicate privately their intended choice of the project alternative, and this choice is binding for the player who ultimately holds the decision right. The intended chosen alternative of the player without decision right will not be relevant, and is unobservable for the other player.

\subsubsection{The Determination of the Probability of Success of the Project}

The player with the decision right not only chooses the project alternative but also the probability of success of the project. The "effort" level-a chosen number-that the player with the decision right devotes to the project determines the probability of success. Effort can be chosen from the set $\{0,1, \ldots, 99,100\}$ and corresponds to the percent probability that the project will be successful. The cost of effort is given by $C(E)=k \cdot E^{2}$ and $C(e)=k \cdot e^{2}$, for the principal and the agent, respectively, where $E$ denotes the principal's effort choice, $e$ the agent's effort choice, and $k \in\{0.01,0.02\}$ is a cost parameter. The cost parameter $k$ varies across rounds, but it is always common knowledge and identical for the principal and the agent. ${ }^{7}$ As with the choice of the alternative, before principals and agents know who will implement the project in a given round, both indicate their intended effort level. This choice is binding for the player who ultimately holds the decision right, and only this player will bear the corresponding cost of effort. The other player's intended effort level will not be executed and no effort costs arise for this player. A player observes neither the intended nor the actual effort choices of the respective other player.

\subsubsection{The Delegation Decision}

In our game, initially the principal always has the right to choose the project alternative and to determine the probability of success. Instead of keeping the decision right, the principal can delegate it to the agent. The principal's delegation decision is contingent on the agent's intended effort choice and on the minimum effort requirement $\underline{e} \in\{1, \ldots, 99,100\}$ that is determined by the principal. ${ }^{8}$ Delegation takes place if and only if the agent's intended effort level $e$ is

\footnotetext{
${ }^{7}$ In the instructions to the participants, both cost functions are presented in a table that displays all possible effort levels and their associated costs. In addition, the instructions contained graphs illustrating the cost functions.

${ }^{8}$ We did not allow for a minimum effort requirement of 0 to ensure a minimal probability of non-delegation. Recall that an agent can choose an effort level of 0 , that is, even if the principal chooses the lowest effort requirement, non-delegation might occur. The principal's own effort and project choice for the case of non-delegation is thus always incentive compatible.
} 


\begin{tabular}{|c|c|c|c|c|}
\hline$t=1$ & $t=2$ & $t=3$ & $t=4$ & $t=5$ \\
\hline 1 & 1 & 1 & 1 & 1 \\
\hline $\begin{array}{l}\text { The agent chooses } \\
\text { an effort level and a } \\
\text { project alternative, } \\
\text { which is binding in } \\
\text { case he receives the } \\
\text { decision right. }\end{array}$ & $\begin{array}{l}\text { Without knowing } \\
\text { the agent's effort } \\
\text { choice, the principal } \\
\text { sets the minimum } \\
\text { effort requirement } \\
\text { conditional on } \\
\text { which she will } \\
\text { delegate the } \\
\text { decision right. }\end{array}$ & $\begin{array}{l}\text { Without knowing } \\
\text { the delegation } \\
\text { outcome, the } \\
\text { principal chooses } \\
\text { an effort level and a } \\
\text { project alternative, } \\
\text { which is binding in } \\
\text { case she retains the } \\
\text { decision right. }\end{array}$ & $\begin{array}{l}\text { The principal is } \\
\text { reminded of all her } \\
\text { choices and of the } \\
\text { resulting monetary } \\
\text { lotteries. She can } \\
\text { change some or all } \\
\text { of her decisions or } \\
\text { reconfirm them. }\end{array}$ & $\begin{array}{l}\text { The decision right } \\
\text { is either delegated } \\
\text { or not. The choices } \\
\text { of the player who } \\
\text { ultimately holds the } \\
\text { decision right are } \\
\text { implemented. }\end{array}$ \\
\hline
\end{tabular}

FIGURE 1.-The order of events in the delegation game.

at least as high as the principal's minimum effort requirement $\underline{e}$. Importantly, the principal does not know the agent's intended effort choice when she sets the minimum requirement. Likewise, the agent does not know the principal's effort requirement when he chooses the intended effort level.

\subsubsection{The Order of Events in the Delegation Game}

The order of the events in the delegation game is shown in Figure 1. First, the agent chooses an intended project alternative and effort level in case he receives the decision right. Both decisions are binding should delegation take place. Second, the principal chooses the minimum effort requirement that-together with the agent's intended effort-determines whether delegation occurs. The principal sets the minimum requirement without knowing the agent's intended effort choice. ${ }^{9}$ Third, before the principal learns whether the agent's intended effort choice matches the minimum requirement, the principal chooses an intended effort level and project alternative for the case in which she retains the decision right. Both decisions are binding should this case materialize. ${ }^{10}$

Next, to ensure that the principals are fully aware of the consequences of all their choices, each principal is reminded of all her choices in the given round. Each principal is explicitly shown the monetary lottery that results for her and for the agent in case she retains the decision right. The principal's effort choice,

\footnotetext{
${ }^{9}$ The principal is also not informed about the agent's choice of the alternative, but subjects chose the alternative with the (weakly) higher monetary payoff for themselves in 97 percent of the cases.

${ }^{10}$ To control for potential order effects, we reversed the order of events in one session so that principals chose their intended effort level and project alternative before determining the minimum effort requirement. We do not find significant differences in mean effort choices $(p=0.61$, two-sample $t$-test) and mean minimum effort requirements ( $p=0.70$, two-sample $t$-test), and therefore pool the data from all sessions in the subsequent analysis.
} 
her corresponding effort cost, and the chosen project alternative fully determine this lottery. At this stage, each principal is also shown a lottery that results for her and for the agent if the agent's effort choice matches exactly the minimum effort requirement and if the agent chooses project alternative $\mathcal{A} \cdot{ }^{11}$ The principals are then given the opportunity to either change some or all of their choices or to reconfirm them.

Finally, the principal's minimum requirement and the agent's intended effort choice are compared to determine whether the decision right is delegated or not, and the decisions of the party who then holds the decision right are implemented. The participants receive no feedback about the outcomes in a given round until the end of the experiment.

\subsubsection{The Parameters in the Different Rounds of the Delegation Game}

Subjects remain in the role of the principal or the agent throughout the experiment. The ten rounds differ only with regard to the payoffs in alternative $\mathcal{P}$ and alternative $\mathcal{A}$ of the project and with regard to the cost of effort. The different parameterizations are implemented to test the robustness of an intrinsic value component of decision rights across different games as well as to test potential situational determinants of this value component. Table I gives an overview of the payoffs in each game. The order of the ten different games was randomized across sessions.

The parameters of the ten games differ systematically with respect to two dimensions. First, the payoffs in games 6 to 10 are exactly twice as high as those in games 1 to 5 . We thus systematically vary the stake size; therefore, games 1-5 are labeled "low stakes" games whereas games 6-10 are labeled "high stakes" games. This is done to address the possibility that the intrinsic value of a decision right is not a fixed monetary amount but varies with the payoffs under consideration.

Second, the games vary the relative monetary difference for the principal and the agent between alternative $\mathcal{P}$ and alternative $\mathcal{A}$ in case of success. We thus systematically vary the conflict of interest between the principal and the agent with respect to the project alternative. Conflict of interest is defined as the principal's relative payoff difference between project alternatives $\mathcal{A}$ and $\mathcal{P}$, denoted as $\alpha=\left(P_{\mathcal{A}}-P_{0}\right) /\left(P_{\mathcal{P}}-P_{0}\right)$. Games 5 and 10 have "no conflict of interest" $(\alpha=1)$, games $1,2,6$, and 7 have a "low conflict of interest" $(\alpha=0.75)$, and games $3,4,8$, and 9 have a "high conflict of interest" $(\alpha=0.5)$. This is done to address the possibility that the intrinsic value of a decision right, just like its

\footnotetext{
${ }^{11}$ Note that this lottery reflects the situation in which the agent chooses the lowest possible effort that is compatible with delegation, that is, among all the possible lotteries that can occur after delegation this is the one with the lowest expected value for the principal. In all other instances of delegation, the agent chooses either a higher effort, which results in a higher success probability, or the principal's preferred project alternative $\mathcal{P}$, or both.
} 
TABLE I

THE PARAMETERS OF THE GAMES ${ }^{a}$

\begin{tabular}{|c|c|c|c|c|c|c|c|c|c|}
\hline & \multicolumn{4}{|c|}{ Project Successful } & & & \multirow[b]{4}{*}{$k$} & & \\
\hline & \multicolumn{2}{|c|}{ Alternative $\mathcal{P}$} & \multicolumn{2}{|c|}{ Alternative $\mathcal{A}$} & \multicolumn{2}{|c|}{ Project Unsuccessful } & & \multirow{2}{*}{\multicolumn{2}{|c|}{ Predicted Values }} \\
\hline & Principal & Agent & Principal & Agent & Principal & Agent & & & \\
\hline & $\left(\boldsymbol{P}_{\mathcal{P}}\right)$ & $\left(A_{\mathcal{P}}\right)$ & $\left(P_{\mathcal{A}}\right)$ & $\left(A_{\mathcal{A}}\right)$ & $\left(P_{0}\right)$ & $\left(A_{0}\right)$ & & $E^{o}$ & $\underline{e}^{o}$ \\
\hline Game 1 & 220 & 190 & 190 & 220 & 100 & 100 & 0.01 & 60 & 40 \\
\hline Game 2 & 280 & 235 & 235 & 280 & 100 & 100 & 0.01 & 90 & 60 \\
\hline Game 3 & 180 & 140 & 140 & 180 & 100 & 100 & 0.01 & 40 & 40 \\
\hline Game 4 & 220 & 160 & 160 & 220 & 100 & 100 & 0.01 & 60 & 60 \\
\hline Game 5 & 260 & 260 & 260 & 260 & 100 & 100 & 0.01 & 80 & 40 \\
\hline Game 6 & 440 & 380 & 380 & 440 & 200 & 200 & 0.02 & 60 & 40 \\
\hline Game 7 & 560 & 470 & 470 & 560 & 200 & 200 & 0.02 & 90 & 60 \\
\hline Game 8 & 360 & 280 & 280 & 360 & 200 & 200 & 0.02 & 40 & 40 \\
\hline Game 9 & 440 & 320 & 320 & 440 & 200 & 200 & 0.02 & 60 & 60 \\
\hline Game 10 & 520 & 520 & 520 & 520 & 200 & 200 & 0.02 & 80 & 40 \\
\hline
\end{tabular}

${ }^{a}$ The table shows the project payoffs in experimental points for principals and agents and the corresponding cost parameter $k$. The table also shows the principals' effort choices, $E^{o}$, and the minimum effort requirements, $\underline{e}^{o}$, that are optimal under the assumption of risk-neutral, selfish preferences and the absence of an intrinsic value component of decision rights.

instrumental value, varies with the conflict of interest between the involved parties.

At the end of the experiment, one of the ten rounds in Part 1 is randomly chosen to be relevant for payment. The player who holds the decision right in that round is given the opportunity to roll two ten-sided dice to determine whether the chosen project alternative is successful or not (unless the relevant effort level is either 0 or 100, in which case the project outcome is certain). The two ten-sided dice generate numbers between 1 and 100 . If this number is below or equal to the chosen percent probability for the project success, then the project is successful. Otherwise, it is unsuccessful. Full feedback about the resulting payoffs is then given to both players.

\subsubsection{Predicted Values for Selfish and Risk-Neutral Principals}

To illustrate the behavioral consequences of the different games for an important benchmark case, we can analyze optimal behavior of the principal under the assumption of selfish and risk-neutral preferences, and the assumption that decision rights carry no intrinsic value. A principal then maximizes her expected monetary payoff in case she keeps control: $\max _{E} E \cdot P_{\mathcal{P}}+(1-E) \cdot P_{0}-$ $C(E)$. Let $E^{o}$ denote the solution to this maximization problem. Given $E^{o}$, the principal then chooses $\underline{e}$ such that the expected monetary payoff in case that the agent chooses exactly $\underline{e}, \underline{e} \cdot P_{\mathcal{A}}+(1-\underline{e}) \cdot P_{0}$, is equal to the maximized pay- 
off in case she keeps control. This yields $\underline{e}^{o}=\frac{\left(E^{o} \cdot\left(P_{\mathcal{P}}-P_{0}\right)-C_{P}\left(E^{o}\right)\right)}{\left(P_{\mathcal{A}}-P_{0}\right)}$. The predicted values $E^{o}$ and $\underline{e}^{o}$ for the different games are displayed in Table I.

\subsection{Part 2: The Lottery Task}

We implement an individual decision task in Part 2 of our experiment. Each principal states her certainty equivalents for 20 different lotteries. Each lottery determines probabilistically the principal's own payoff and the payoff of another, randomly paired participant. These 20 lotteries are determined by a principal's own choices in the ten rounds of the preceding delegation game. ${ }^{12}$ In each round of the delegation game, a principal's choice of $E$, $\underline{e}$, and the project alternative defines a pair of lotteries: a control lottery and a delegation lottery. ${ }^{13}$ A principal's intended effort choice, her corresponding effort costs, and the chosen project alternative fully determine a control lottery. The minimum effort requirement fully determines a delegation lottery. By definition, the latter occurs if an agent chooses exactly the principal's minimum effort requirement, incurs the associated effort cost, and chooses project alternative $\mathcal{A}$.

For example, assume that a principal chooses an intended effort level of $E=50$ (with an associated effort cost of 25), alternative $\mathcal{P}$, and a minimum effort requirement of $\underline{e}=40$ (with an associated effort cost of 16 for the agent) in game 1 of Part 1 of the experiment (see Table I). These choices imply the following two lotteries over the own and another participant's payoff:

- Control Lottery: The principal receives $220-25=195$ experimental points and the agent receives 190 points with a probability of 0.5 , and the principal receives $100-25=75$ points and the agent receives 100 points with a probability of 0.5 .

- Delegation Lottery: The principal receives 190 points and the agent receives $220-16=204$ points with a probability of 0.4 , and the principal receives 100 points and the agent receives $100-16=84$ points with a probability of 0.6 . Importantly, the control lottery and the delegation lottery are exogenously given in the lottery task. In particular, we do not inform the principals that the 20 lotteries that they face in Part 2 are derived from their own choices in Part 1 . The principals simply face each of the 20 exogenously given lotteries in an individually randomized order and specify their certainty equivalents.

To elicit a principal's certainty equivalents, we use an incentive compatible mechanism first introduced by Becker, DeGroot, and Marschak (1964). For ev-

\footnotetext{
${ }^{12}$ Here we refer to participants who are in the role of a principal in Part 1 of the experiment as "principals" and to the other participants as "agents" for expositional reasons only. In the instructions to Part 2, participants are not called principals and agents; each participant is simply referred to as "you," and a matched participant whose payoff might be affected by one's own choice is referred to as a "random other participant."

${ }^{13}$ In the participants' instructions to Part 2, the 20 lotteries are not labeled in this way, nor are they distinguished in any other way. We introduce these terms here for expositional reasons only.
} 
ery lottery, a principal has to indicate the smallest certain payoff-the certainty equivalent - that she demands in order to be willing to accept the certain payoff instead of the lottery. A computerized random mechanism then determines the certain payoff actually offered to the principal. The offered certain payoff is drawn from a uniform distribution, where the bounds of the distribution are given by the two possible lottery payoffs for the principal. In the example of the control lottery above, the principal's actual certain payoff is thus uniformly distributed between 75 and 195 points. If the actually offered certain payoff is at least as high as the stated certainty equivalent, the principal receives the actual certain payoff and the lottery is not played in this case. If the actual certain payoff is below the stated certainty equivalent, the lottery is played. Since principals face lotteries over their own as well as over a randomly matched other participant's income, we also need to determine a payment to the respective other participant in case the certain payment is chosen. ${ }^{14}$ In the lotteries derived from the choices in games 1 to 5 , this fixed payment is 100 points, while it is 200 points in the lotteries that are derived from the choices in games 6 to 10. These payments match those of the projects in Part 1 in case of failure.

At the end of the experiment, two of the 20 lotteries are randomly chosen to be relevant for payment. ${ }^{15}$ Each principal is given feedback about the size of the actually offered certain payoff for these lotteries. In case the actually offered certain payoff exceeds the principal's demanded certainty equivalent, the principal receives the offered certain payoff and the other participant receives the associated fixed payment, that is, the lottery is not played out. In case a principal's demanded certainty equivalent exceeds the actually offered certain payoff, the lottery is played out. The principal is then given the opportunity to roll two ten-sided dice to determine the lottery outcome. Feedback is finally given to all participants. ${ }^{16}$

\footnotetext{
${ }^{14}$ In this regard, our experiment is different from a typical experimental certainty equivalent elicitation task, in which lotteries and certainty equivalents involve only payments for the decision maker. Comparability with the lotteries in Part 1 makes it necessary to evaluate lotteries with payments to two parties. To avoid a stark discrepancy between the cases where the lottery is chosen and where the certain payment is chosen, the matched participant also receives a fixed payment in the latter case. Importantly, the fixed payment to the matched participant is constant within each pair of control lottery and delegation lottery.

${ }^{15}$ Since 1 out of 10 rounds was selected for payment in Part 1 , we selected 2 out of 20 lotteries in Part 2, to keep the selection probability constant.

${ }^{16}$ In Part 2, also the agents played the lottery task. This was done to entertain them during Part 2. Each principal thus also assumed the role of the "random other participant" in two randomly chosen lotteries and was paid according to the respectively matched agent's choices. The participants were only informed about the additional earnings in the role of the "random other participant" at the end of the experiment. Our matching algorithm ensured that no participant was matched with another participant more than once in Part 2.
} 


\subsection{Further Experimental Measurements}

Subsequent to Parts 1 and 2, further individual measures are taken. First, we elicit a participant's loss aversion. Second, we measure a participant's illusion of control. We collect these additional measures to analyze possible alternative explanations for a difference in certainty equivalents in Part 2 . The additional measures are described in more detail in Section 5.

\subsection{Procedures}

We conducted three sessions with a total of 104 participants at the computer laboratory of the Department of Economics at the University of Zurich in October 2011 and two additional control sessions with a total of 68 subjects in November 2012. The subject pool consisted primarily of students at the University of Zurich and the Swiss Federal Institute of Technology in Zurich. The experiments were computerized using the software Z-Tree (Fischbacher (2007)) and the recruitment was done with the software ORSEE (Greiner (2004)). An experimental session lasted 2 to 3 hours.

The participants were provided with written instructions and-in the first two parts of the experiment-had to answer control questions to guarantee their understanding of the instructions. Instructions for the lottery task in Part 2 of the experiment were handed out only after the delegation game in Part 1 was finished. Participants knew that the experimental session would consist of several parts, but they did not know the content of the future parts before the respective instructions were provided. The instructions for the loss aversion task were presented on a computer screen; the instructions for the illusion of control task were paper based. An English translation of all instructions can be found in the Supplemental Material (Bartling, Fehr, and Herz (2014)).

Payments were made for one randomly drawn round of the delegation game and for four randomly drawn lotteries in Part 2 (two of them in the role of the "random other participant"; see footnote 16). Subjects received additional payments in the loss aversion and illusion of control tasks. One hundred experimental points were converted into $6 \mathrm{CHF}$, which resulted in an average payment of 75 CHF ( $\$ 80.00$ at the time of the experiment), including a 10 CHF show-up fee.

\section{THEORETICAL FRAMEWORK}

We begin with analyzing the principal's decision problem assuming no intrinsic value of decision rights, and then extend the analysis to show how our mechanism allows measuring the intrinsic value.

\subsection{The Principal's Optimal Decision}

Let the principal's utility function over lotteries be given by $U(L)$. In our context, a lottery $L$ is defined by $L=\left(x_{s}^{\omega}, x_{f}^{\omega}, p\right)$, where $x_{s}^{\omega}$ and $x_{f}^{\omega}$ denote 
the outcome vectors in case the chosen project is successful $(s)$ or a failure $(f)$, respectively, $p$ denotes the probability of success, and $\omega \in\{c, d\}$ denotes whether the principal holds control $(c)$ or whether control was delegated $(d)$. Each outcome vector specifies monetary payoffs, $x_{j}^{\omega}=\left(\begin{array}{c}x_{j, P}^{\omega} \\ x_{j, A}^{\omega}\end{array}\right), j=\{s, f\}$, where $x_{j, P}^{\omega}$ denotes the monetary payoff to the principal and $x_{j, A}^{\omega}$ denotes the monetary payoff to the agent. The principal's utility over certain monetary outcomes is further given by $u\left(x_{j, P}^{\omega}, x_{j, A}^{\omega}\right)$.

In Part 1 of the experiment, the principal chooses an effort level $E$ as well as a project alternative $\theta_{P} \in\{\mathcal{A}, \mathcal{P}\}$ for the case that she keeps control. These choices determine the probability of success, $p(E)=E / 100$, as well as the payoff vectors in case of success and failure, $x_{s}^{c}\left(E, \theta_{P}\right)=\left({ }_{\theta_{\theta_{\theta_{P}}}-C(E)}\right)$ and $x_{f}^{c}(E)=\left(\begin{array}{c}P_{0}-C(E) \\ A_{0}\end{array}\right)$. Thus, the principal solves the following maximization problem:

$$
\begin{aligned}
\max _{E, \theta_{P}} U\left(L\left(x_{s}^{c}, x_{f}^{c}, p\right)\right)= & E \cdot u\left(P_{\theta_{P}}-C(E), A_{\theta_{P}}\right) \\
& +(1-E) \cdot u\left(P_{0}-C(E), A_{0}\right) .
\end{aligned}
$$

Denote the solution to this maximization problem by $E^{*}$ and $\theta_{P}^{*}$. These choices define the control lottery, which we denote by

$$
L^{c}=L\left(x_{s}^{c}\left(E^{*}, \theta_{P}^{*}\right), x_{f}^{c}\left(E^{*}\right), p\left(E^{*}\right)\right) .
$$

Second, in case of delegation, the agent's effort choice $e$ and his project choice $\theta_{A} \in\{\mathcal{A}, \mathcal{P}\}$ determine the probability of success, $p(e)=e / 100$, as well as the payoff vectors in case of success and failure, $x_{s}^{d}\left(e, \theta_{A}\right)=\left(\begin{array}{c}P_{\theta_{A}} \\ A_{\theta_{A}}-C(e)\end{array}\right)$ and $x_{f}^{d}(e)=\left(\begin{array}{c}P_{0} \\ A_{0}-C(e)\end{array}\right)$. Since $x_{s}^{d}, x_{f}^{d}$, and $p$ are determined by $e$ and $\theta_{A}$, we denote the lotteries in case of delegation by

$$
L^{d}\left(e, \theta_{A}\right)=\left(x_{s}^{d}\left(e, \theta_{A}\right), x_{f}^{d}(e), p(e)\right) .
$$

We can now determine the principal's optimal choice of the minimum effort requirement after imposing some additional structure on the principal's utility function over delegation lotteries. First, we assume that the principal's utility from a delegation lottery is increasing in the probability of success and, second, that the principal weakly prefers if the agent chooses project alternative $\mathcal{P}$ :

AsSUMPTION 1:

$$
\frac{\partial U\left(L^{d}\left(e, \theta_{A}\right)\right)}{\partial e}>0 .
$$

ASSUMPTION 2:

$$
U\left(L^{d}(e, \mathcal{P})\right) \geq U\left(L^{d}(e, \mathcal{A})\right) .
$$


Both assumptions are reasonable: A higher agent effort increases $p(e)$ without affecting $x_{j, P}^{d}$, and hence increases her expected monetary payoff. The same holds if the agent chooses project alternative $\mathcal{P}$ rather than $\mathcal{A}$. Both assumptions are thus trivially satisfied for a purely self-interested principal. We discuss potential implications of social preferences below. ${ }^{17}$

The delegation mechanism in our experimental delegation game allows the principal to set a minimum effort requirement $\underline{e}$ such that decision rights are only delegated in case $e \geq \underline{e}$. Under Assumptions 1 and 2 , it therefore follows that the worst lottery that the principal may face after delegation is realized if the agent chooses $e=\underline{e}$ and project alternative $\mathcal{A} .{ }^{18}$ We call this worst lottery the delegation lottery, defined as

$$
L^{\underline{d}}=L^{d}(\underline{e}, \mathcal{A}) .
$$

Assumption 1 implies that the principal's utility is weakly increasing in the agent's effort choice. Consequently, the principal should optimally choose her minimum effort requirement $\underline{e}^{*}$ such that she delegates whenever delegation makes her better off compared to keeping the decision right, and she keeps the decision right whenever delegation would make her worse off compared to keeping the decision right. Figure 2 illustrates this decision.

Suppose the principal sets the minimum effort requirement below $\underline{e}^{*}$, say at $\underline{\tilde{e}}<\underline{e}^{*}$, such that $U\left(L^{c}\right)>U\left(L^{d}(\underline{\tilde{e}}, \mathcal{A})\right)$. It can then happen that the agent chooses an effort level that is strictly in the interval $\left[\underline{\tilde{e}}, \underline{e}^{*}\right]$, so that delegation occurs but yields a strictly lower utility to the principal than $U\left(L^{c}\right)$. A similar argument applies if the minimum effort requirement is set above $\underline{e}^{*}$. Consequently, it is optimal for the principal to set the minimum effort requirement such that the utility of the control lottery is just equal to the utility of the delegation lottery:

$$
U\left(L^{c}\right)=U\left(L^{\underline{d}}\right)
$$

Given Assumption 1, equation (4) has a unique solution if the following assumption holds:

\section{ASSUMPTION 3:}

$$
U\left(L^{d}(e=100, \mathcal{A})\right) \geq U\left(L^{c}\right) \geq U\left(L^{d}(e=1, \mathcal{A})\right) .
$$

\footnotetext{
${ }^{17}$ In principle, Assumptions 1 and 2 are empirically testable, but we refrained from doing this because we considered it highly unlikely that they will be violated.

${ }^{18}$ For the remainder of this section, we assume that the principal believes that the agent chooses project alternative $\mathcal{A}$. Indeed, 97 percent of subjects chose the alternative that gave them the higher expected payoff. Nonetheless, it may be the case that the principal believes that the agent chooses project $\mathcal{P}$ in case of delegation. Later in this section, we discuss that such beliefs can only bias our measurement of the intrinsic value of decision rights downwards, and we would hence underestimate the intrinsic value. Constructing the delegation lotteries using project alternative $\mathcal{A}$ is thus conservative.
} 


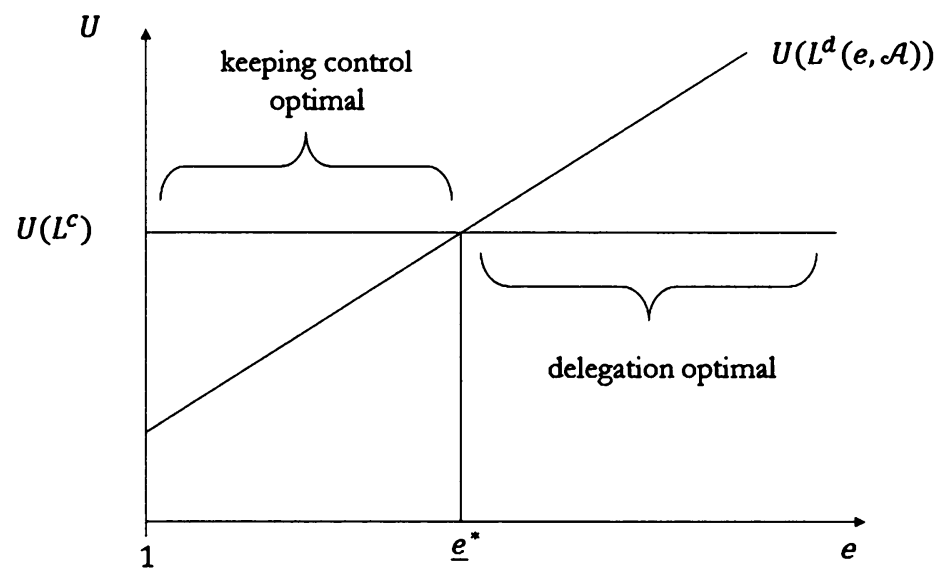

FIGURE 2.-The principal's utility in case of keeping control and delegation as a function of the agent's actual effort.

If the principal prefers to keep the decision right in case the agent provides the lowest possible effort $(e=1)$, and if she prefers delegating the decision right in case the agent chooses the maximum possible effort $(e=100)$, then it follows from Assumption 1 that there exists some $e$ such that equation (4) is satisfied. ${ }^{19}$

\subsection{Measuring the Intrinsic Value of Decision Rights}

Equation (4) provides the basis for measuring the intrinsic value of decision rights. The equation determines a control lottery and a delegation lottery that yield the same utility for the principal in the delegation game. Let the certainty equivalent $\operatorname{CE}(L)$ denote the certain payment to the principal that makes the principal just indifferent between the exogenously given lottery $L$ and certain payments of $\operatorname{CE}(L)$ to the principal and $A_{0}$ to the agent (remember that this is the payment to the agent in case the certain payment is chosen in Part 2 of the experiment). If the principal does not assign any utility to the decision right per se, equation (4) can only be satisfied if the certainty equivalent of the control

\footnotetext{
${ }^{19}$ Note first that Assumption 3 is clearly met for all parameters in our experiment, assuming pure self-interest and risk neutrality. But if $U\left(L^{c}\right)<U\left(L^{d}\left(e=1, \theta_{A}\right)\right)$, the principal may always want to delegate and thus choose the lowest possible $\underline{e}$, and if $U\left(L^{c}\right)>U\left(L^{d}\left(e=100, \theta_{A}\right)\right)$, the principal may never want to delegate and thus choose the highest possible $\underline{e}$. Consequently, chosen values of $\underline{e}=1$ or $\underline{e}=100$ may not reflect the principal's point of indifference between keeping control and delegation. If we observe choices of the lowest (highest) possible $\underline{e}$, we may therefore overestimate (underestimate) the intrinsic value of decision rights. In Section 5.5, we present evidence from a control treatment showing that we are not overestimating the intrinsic value of decision rights for principals who choose the lowest possible $\underline{e}$.
} 
lottery, $\operatorname{CE}\left(L^{c}\right)$, is equal to the certainty equivalent of the delegation lottery, $\mathrm{CE}\left(L^{\underline{d}}\right)$ :

$$
\begin{aligned}
& u\left(\operatorname{CE}\left(L^{c}\right), A_{0}\right)=u\left(\operatorname{CE}\left(L^{\underline{d}}\right), A_{0}\right), \\
& \operatorname{CE}\left(L^{c}\right)=\operatorname{CE}\left(L^{\underline{d}}\right) .
\end{aligned}
$$

Therefore, in Part 2, where we confront the principals with the exogenously given control and delegation lotteries that they determined in the delegation game by their choices of $E^{*}, \theta_{P}$, and $\underline{e}^{*}$, the certainty equivalents of the respective pairs of lotteries should be identical.

However, if decision rights carry value per se, utility needs to be defined not only over lotteries, but also over the allocation of decision rights: $U(L, \omega)$, where $\omega \in\{c, d\}$ denotes the allocation of decision rights. ${ }^{20}$ If decision rights are per se valuable, indifference in the delegation game implies

$$
U\left(L^{c}, c\right)=U\left(L^{\underline{d}}, d\right)
$$

The certainty equivalents of the exogenously given lotteries, $\operatorname{CE}\left(L^{c}\right)$ and $\mathrm{CE}\left(L^{d}\right)$, do not contain the potential intrinsic value of decision rights. To account for the potential intrinsic value, we define $V_{\omega}$ as the (possibly negative) monetary measure of the principal's intrinsic value associated with either having the decision right $(\omega=c)$ or not having the decision right $(\omega=d)$. Therefore, $V_{c}$ captures potential intrinsic utility components of being in control, whereas $V_{d}$ captures (potentially negative) intrinsic utility components of being in a subordinate position. We can then define the following identity:

$$
U\left(L^{\omega}, \omega\right)=u\left(\operatorname{CE}\left(L^{\omega}\right)+V_{\omega}, A_{0}\right)
$$

Equations (7) and (8) therefore imply that $u\left(\operatorname{CE}\left(L^{c}\right)+V_{c}, A_{0}\right)=$ $u\left(\mathrm{CE}\left(L^{\underline{d}}\right)+V_{d}, A_{0}\right)$. If keeping the decision right is preferred over transferring the decision right $\left(V_{c}>V_{d}\right)$, equation (7) can only hold if $\operatorname{CE}\left(L^{c}\right)$, that is, the instrumental value of the decision right, is lower than $\operatorname{CE}\left(L^{\underline{d}}\right)$. In other words, the principal is only willing to transfer the decision right if she is compensated monetarily.

\footnotetext{
${ }^{20}$ Note that Assumptions 1-3 must be satisfied for a principal's utility function defined over lotteries and decision rights, $U(L, \omega)$, while-for expositional reasons-we stated it above for $U(L)$ only.
} 
We can thus quantify the potential intrinsic value of decision rights as the certain amount of money that a principal demands as a compensation for the transfer of the decision right: ${ }^{21}$

$$
\text { Intrinsic Value of Decision Right }=V_{c}-V_{d}=\mathrm{CE}\left(L^{\underline{d}}\right)-\mathrm{CE}\left(L^{c}\right) .
$$

\subsection{Discussion}

It is important to note that, given Assumptions 1 and 2, our measure of the intrinsic value accounts for the principals' unobserved risk and social preferences. First, the indifference point between the control and the delegation lottery is endogenously chosen based on the principal's unobserved risk and social preferences. Since the monetary payoff consequences of the control and delegation lottery are unchanged when they are presented as exogenously given lotteries in Part 2, these preferences similarly enter the determination of the certainty equivalents in Part 2 . However, extreme forms of inequity aversion may violate Assumption 1 or 2 , in which case there may not be a unique indifference point which implicitly determines the principal's compensation request for giving up her decision right. For example, although an increasing $e$ always increases the principal's expected payoff, it may also increase advantageous inequality, and if the principal strongly dislikes this inequality her expected utility may not increase. However, such extreme forms of inequality aversion are implausible. ${ }^{22}$

Moreover, our measure of the intrinsic value is independent of beliefs about the agent's effort. It depends only on the minimum effort requirement $\underline{e}$, which does not depend on the agent's actually chosen effort. This implies that ambiguity about the agent's effort choice cannot affect the measurement. Moreover, the intrinsic value is calculated based on the conservative assumption that the agent chooses project alternative $\mathcal{A}$ in case of delegation. In principle, it may be the case that the principal believes that the agent chooses project $\mathcal{P}$ with positive probability in case of delegation. This would imply that the principal chooses $\underline{e}$ such that $E_{\theta_{A}}\left[U\left(L^{d}\left(\underline{e}, \theta_{A}\right)\right)\right]=U\left(L^{c}\right) \geq U\left(L^{\underline{d}}\right)$, that is, the control lottery is weakly preferred to the delegation lottery as defined in (3).

\footnotetext{
${ }^{21}$ Equation (9) shows that our design does not allow disentangling whether a possible positive intrinsic value of decision rights stems from the desire to be able to affect someone else's payoffs (as is the case if the principal keeps control) or from the aversion to be affected by some else's decision (as in case of delegation to the agent), or both. Addressing this question is an interesting topic for future research.

${ }^{22}$ There are several reasons for this. First, the structure of the delegation game often involves the choice between advantageous and disadvantageous inequality rather than the removal of any form of inequality. In such situations, individuals typically prefer advantageous over disadvantageous inequality. Second, if delegation occurs, the agent chooses his utility maximizing effort level (and project variant). Thus, if the agent chooses a very high effort level (or project variant $\mathcal{P}$ ) that causes advantageous inequality for the principal, the agent is himself responsible for this inequality, which is likely to mitigate the principal's inequality concerns.
} 
Note that this inequality even holds if the principal is ambiguity averse, because $L^{\underline{d}}$ denotes the worst possible lottery in the support of the principal's beliefs. This biases our measurement of the intrinsic value of decision rights, as defined in (9), downwards, since $\operatorname{CE}\left(L^{d}\left(\underline{e}, \theta_{A}\right)\right)$ is smallest if $\theta_{A}=\mathcal{A}$. Consequently, if principals indeed believed that project alternative $\mathcal{P}$ is chosen with positive probability, we would underestimate the intrinsic value of decision rights.

\section{RESULTS}

\subsection{The Intrinsic Value of Decision Rights}

Our first result concerns the question whether principals assign intrinsic value to their decision rights:

RESULT 1-Intrinsic Value of Decision Rights: The large majority of the principals value the delegation lotteries significantly more than the corresponding control lotteries. Thus, on average, principals value decision rights intrinsically.

Figure 3 shows each principal's average certainty equivalent of the control lotteries on the horizontal axis and each principal's average certainty equivalent of the delegation lotteries on the vertical axis. Each of the 69 dots in Figure 3 thus represents one principal.

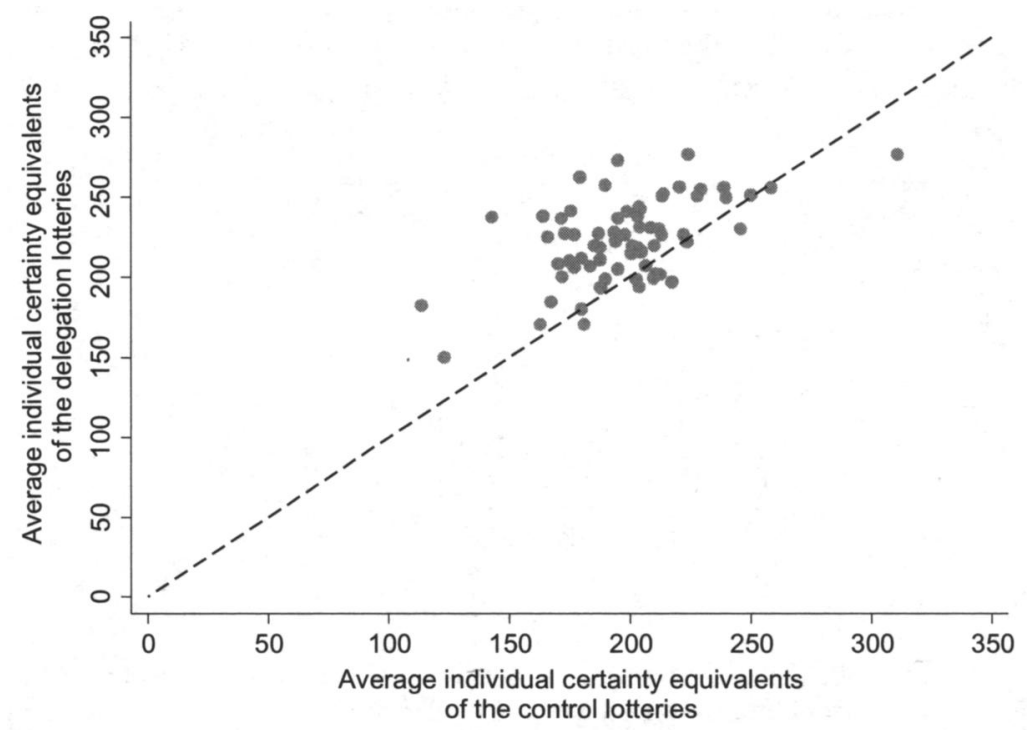

FIGURE 3.-Individual principals' average certainty equivalents of the control lotteries and the delegation lotteries in experimental points. Each of the 69 dots represents one principal. The figure shows that most principals value the delegation lotteries on average higher than the control lotteries. 
If principals derive no intrinsic utility from decision rights, the average individual certainty equivalents of these lotteries should be equal and thus lie on the $45^{\circ}$ line. It is evident from Figure 3, however, that the majority of observations lie above the $45^{\circ}$ line. On average, the certainty equivalents of the delegation lotteries are 16.7 percent larger than those of the control lotteries. A one-sample $t$-test ${ }^{23}$ shows that this percentage difference is significantly larger than zero $(p<0.001)$. This indicates that, on average, the principals assign a positive intrinsic value to decision rights.

Figure 3 also reveals considerable individual heterogeneity in the intrinsic value of decision rights. The standard deviation in the average percentage difference between the certainty equivalents of the delegation and control lotteries is 15.6 percent. The large majority of principals assign positive intrinsic value to decision rights, while only a minority assigns a negative value. Eightythree percent of the principals assign on average higher certainty equivalents to the delegation lotteries, whereas 17 percent of the principals do the opposite. A nonparametric Wilcoxon signed-rank test rejects the hypothesis that principals value the delegation lotteries and the control lotteries equally $(p<0.001)$.

To test the robustness of our main result, we analyze whether we consistently measure a positive intrinsic value of decision rights in all ten delegation games. Figure 4 shows the average percentage difference between principals' certainty equivalents of the delegation lotteries and control lotteries for all ten delegation games. The figure shows that the principals assign higher certainty equivalents to the delegation lotteries in each of the ten delegation games, and the difference is statistically significant at the 1 percent level in nine out of ten games in both a one-sample $t$-test and the Wilcoxon signed-rank test. Game 9

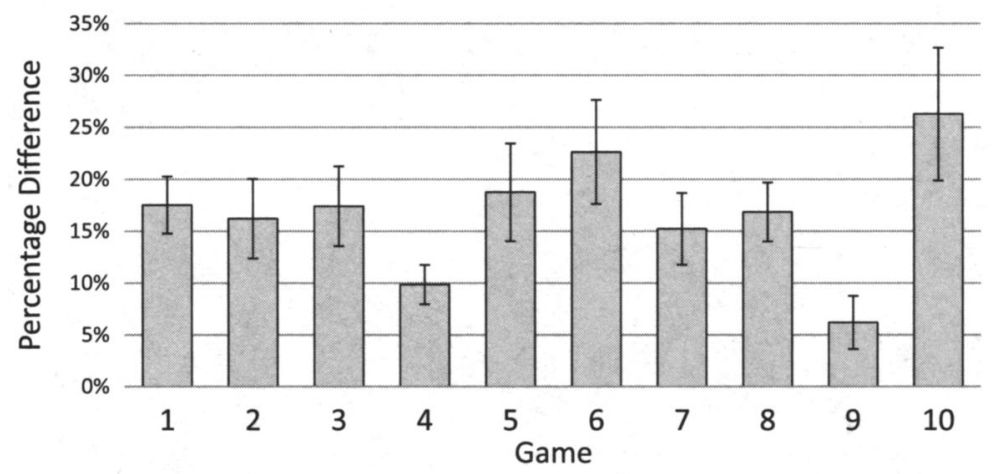

FIGURE 4.-Average percentage difference between the certainty equivalents of the delegation lotteries and control lotteries, sorted by delegation game. Error bars represent one standard deviation of the percentage difference in the certainty equivalents.

\footnotetext{
${ }^{23} \mathrm{We}$ use the average percentage difference in certainty equivalents of each principal as one observation to perform the $t$-test. All reported $p$-values refer to two-sided tests.
} 
is significant at the 5 and 10 percent level only $(p=0.02, t$-test and $p=0.06$, Wilcoxon signed-rank test). ${ }^{24}$

This finding is summarized in the following result:

RESUlT 2-Intrinsic Value of Decision Rights in the Separate Games: The intrinsic value of decision rights is significantly positive in all ten delegation games.

The observation that a positive intrinsic value of decision rights is found not only in most principals, but also across the different delegation games, lends support to the robustness of our finding. ${ }^{25}$

The elicitation of the certainty equivalents in Part 2 is time consuming and researchers interested in measuring the intrinsic value of a decision right may, therefore, want to rely on a simpler proxy measure in some environments. The expected values of the delegation and control lotteries generated in Part 1 may provide the basis for such a proxy measure. For this proxy to be useful, the expected monetary payoffs of the delegation and control lotteries should be highly correlated with the certainty equivalents. We find that this is indeed the case. The pairwise correlation between a principal's expected payoff and the elicited certainty equivalent of a lottery is $\rho=0.89$, which is highly significant $(p<0.001)$. Moreover, our measure of the intrinsic value of decision rights (the difference in the certainty equivalents of the corresponding control and delegation lotteries) is positively correlated with the respective difference in the principal's expected payoffs between these two lotteries $(\rho=0.58$, $p<0.001)$.

Equivalently to Result 1 , we find that the expected payoffs of the delegation lotteries are on average larger than the expected values of the control lotteries; the difference amounts to 7.1 percent. A one-sample $t$-test shows that this percentage difference is highly significant $(p<0.001) .{ }^{26}$ Moreover, the average difference in expected payoffs is positive for 82.6 percent of the principals, which is almost identical to the percentage of principals ( 83 percent) who value

\footnotetext{
${ }^{24}$ We perform these tests using each principal's percentage difference between the certainty equivalents of the delegation and control lotteries as an observation.

${ }^{25}$ Further support for the robustness of our results can be found in one of the authors' Ph.D. thesis. In Herz (2011), 12 delegation games (all with payoffs different from those in this paper) were used to elicit the intrinsic value of decision rights. The findings confirm the results presented here. The average percentage difference in certainty equivalents between the delegation and control lotteries is highly significant and amounts to 14.2 percent, a large and highly significant majority of 92 percent of principals ( 33 out of 36 ) positively values decision rights, and the finding is robust across all games (significantly so at the 1 or 5 percent level in 10 out of 12 games). The experimental design here amends the design reported in Herz (2011), especially with regard to their sequential structure, it varies the payoffs more systematically, for example with respect to the conflict of interest and the stake size of the decision, and it adds additional measures.

${ }^{26}$ To perform the $t$-test, we averaged the percentage differences in expected values for each principal.
} 
decision rights positively when this value is measured on the basis of certainty equivalents $(p<0.001$, Wilcoxon signed-rank test).

Analogously to Result 2, we find that the principals' average expected payoffs in the delegation lotteries are larger than those in the control lotteries in all delegation games. These differences are significant at least at the 5 percent level for eight of the ten delegation games using one-sample $t$-tests or Wilcoxon signed-rank tests. ${ }^{27}$

Finally, we analyze whether the intrinsic value of decision rights is measured consistently across principals in the ten delegation games. Consistency would require that if principal $i$ assigns a higher intrinsic value to decision rights than principal $j$ in one game, then principal $i$ also assigns a higher value in the other games, that is, that individual intrinsic values are correlated across games. One way to assess this consistency is to compute Cronbach's alpha, a concept frequently used in psychology and other social sciences as a measure of the internal validity of a psychometric test score (Cronbach (1951)). Cronbach's alpha measures the extent to which different items in questionnaires or-for our purposes-economic games measure the same latent variable. To measure this correlation, one could compute the correlation of the average intrinsic value of decision rights between the first five games and the last five games. Since this split is arbitrary, Cronbach's alpha is the mean of all possible split-half correlations of the games: Formally, Cronbach's alpha $=\frac{N}{N-1}\left(1-\frac{\sum_{j=1}^{N} \operatorname{var}\left(x_{j}\right)}{\operatorname{var} \sum_{j=1}^{N} x_{j}}\right)$, where $N$ is the number of games (ten in our case), $\operatorname{var}\left(x_{j}\right)$ is the variance of the measured values in the $j$ th game, and $\operatorname{var} \sum_{j=1}^{N} x_{j}$ is the variance of the sum of the measured values in the $N$ games. Cronbach's alpha thus measures the correlation between the games, and it varies between zero and unity. Cronbach's alpha is equal to 0.62 when we consider the percentage difference in certainty equivalents and equal to 0.77 when we consider the percentage difference in expected values. This suggests a relatively strong positive correlation of our intrinsic value measures across principals in the ten games.

\subsection{Situational Determinants of the Intrinsic Value of Decision Rights}

In this subsection, we identify two situational determinants of the intrinsic value of decision rights. Figure 4 reveals that the intrinsic value varies across the ten different delegation games. This raises the question how situational characteristics, that is, game specific factors, affect the intrinsic value of decision rights. As we described in Section 2.1.6, our experimental design enables us to consider two potential drivers: (i) the stake size and (ii) the conflict of interest.

\footnotetext{
${ }^{27}$ In games 5 and 9 , the $p$-values are $p=0.31$ and $p=0.09$ for the $t$-tests; for the Wilcoxon signed-rank test, the $p$-values are $p=0.50$ and $p=0.06$, respectively.
} 

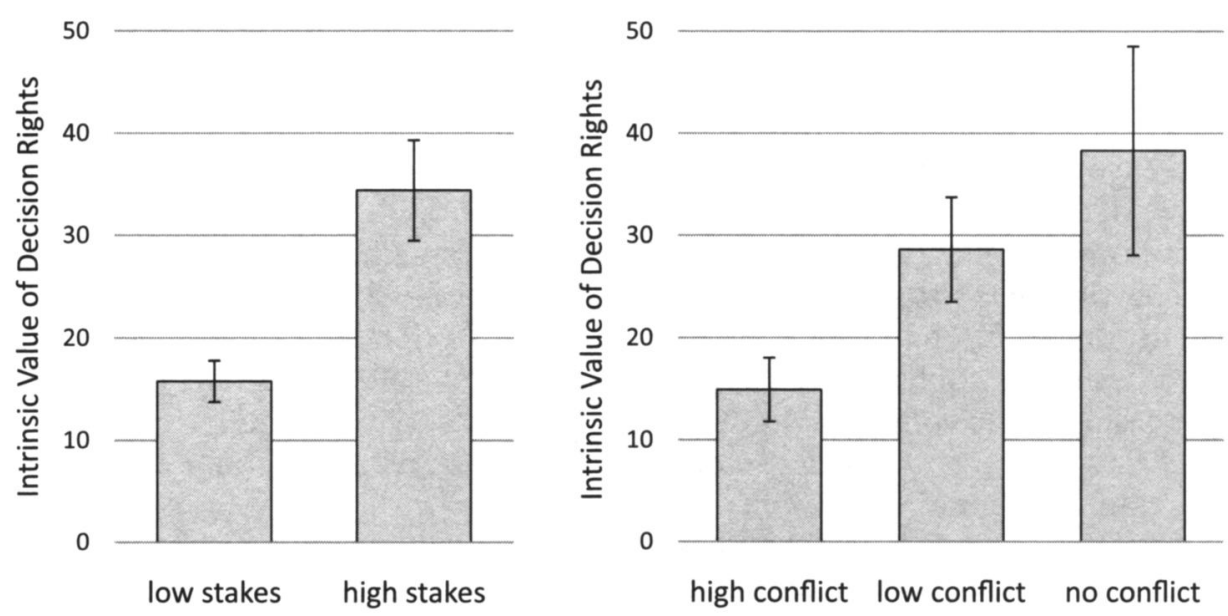

FIGURE 5.-The left panel shows the average intrinsic value of decision rights by stake size. The right panel shows the average intrinsic value of decision rights by conflict of interest. The bars display one standard deviation of the mean.

The stake size is systematically varied between the "low stakes" games (1-5) and "high stakes" games (6-10). We are interested in whether the intrinsic value of a decision right is simply a fixed amount, or whether it systematically varies with the monetary amounts under consideration. The left panel of Figure 5 shows the average intrinsic values of decision rights for the two stake size levels. It can be seen that decision rights are valued about twice as high in the high stakes games. The difference amounts to 18.6 experimental points and is statistically highly significant $(p<0.001, t$-test; $p<0.001$, Wilcoxon signed-rank test). ${ }^{28}$ This suggests that the intrinsic value of decision rights is not simply a small, fixed value but that it indeed scales with the stakes involved in the decision. This finding is summarized in the following result:

RESULT 3-Stake Size: The intrinsic value of decision rights increases with the monetary amounts at stake.

The conflict of interest between the principal and the agent is systematically varied across games by varying the principal's relative payoff difference between project alternatives $\mathcal{A}$ and $\mathcal{P}$. We hypothesize that the conflict of interest between the involved parties is a driving factor not only of the instrumental value but also of the intrinsic value of decision rights. This hypothesis is motivated by debates about the definition of power in the political science literature. While some scholars define power simply as being "able to make, or

\footnotetext{
${ }^{28}$ The intrinsic value is again first averaged for each principal before a one-sample $t$-test is performed.
} 
able to receive, any change" (Locke (1975[1690], p. 111)), others postulate that these choices must affect another party with conflicting interests to constitute power (Dahl (1957), Polsby (1963), Lukes (2005)). The systematic variation of the payoffs across the different games allows us to analyze how the intrinsic value of decision rights changes when the conflict of interest changes, or when there is no conflict of interest in the choice of the alternative at all.

The right panel of Figure 5 shows the average intrinsic values of decision rights for the different levels of conflict of interest. If individuals are motivated by a desire for control over another individual, and if the degree of power is increasing in the conflict of interest, we should observe that the intrinsic value of decision rights (granting power over another individual) should increase if the conflict of interest between parties increases.

Our data do not support this view, and in fact point in the opposite direction. Figure 5 shows that the intrinsic value of decision rights is higher when there is no conflict of interest. While the difference between the intrinsic values of decision rights is not statistically significantly different between low conflict and no conflict of interest, the intrinsic value is significantly smaller under high conflict of interest compared to both low and no conflict of interest $(p<0.01$, respectively, using paired $t$-tests or Wilcoxon signed-rank tests). This is summarized in the following result:

RESULT 4-Conflict of Interest: The intrinsic value of decision rights is higher, the lower the conflict of interest between the principal and the agent.

One should remember that the instrumental value of decision rights increases as the conflict of interest increases, since enforcing the own preferred choice becomes more important. The widely held intuition that individuals' value power, control, or decision rights particularly in situations in which there is "conflict" is therefore not necessarily wrong, but it is likely to be driven by its instrumental value. A possible explanation for Result 4 is that making decisions that are also in the best interest of another person are "comfortable" decisions to make. Subjects may derive more self-esteem from successful implementation if their actions also profited another person. If, however, own actions impinge upon the interests of another person, these psychic benefits might be reduced. Our data do not allow us to pin down all the relevant and potentially contrarious situational determinants of the intrinsic value of decision rights. In future research, it would thus be interesting to disentangle the driving forces behind Result 4 , and to learn more about the situational determinants of the intrinsic value of decision rights in general.

\section{ALTERNATIVE EXPLANATIONS}

We attribute the differences in certainty equivalents to an intrinsic preference for decision rights, but are there alternative explanations? We already 
showed in Section 3 that risk and social preferences as well as ambiguity aversion cannot explain our results, because we controlled for these preference dimensions with the experimental design. In this section, we explore and discuss further potential alternative explanations.

\subsection{Loss Aversion}

Loss aversion (Kahneman and Tversky (1979)) might be a partial explanation for the observed size of the difference in certainty equivalents. A principal initially holds the decision right, and parting with this right might be perceived as a loss. It is important to remember, however, that some value has to be present for a loss to be perceived. Hence, loss aversion cannot fully explain the difference in the certainty equivalents, but it might contribute to its size.

In the final part of the experiment, we elicited an individual's degree of loss aversion using lottery tasks, where subjects had to accept or reject a series of lotteries involving possible losses of different sizes $X .^{29}$ The participants' decisions allow us to measure their loss aversion. The amount $X$ at which a participant starts rejecting the lotteries is an indicator of his or her loss aversion. For example, a participant who rejects all lotteries with a potential loss of $X>3$ is classified as more loss averse than a participant who only rejects all lotteries with a potential loss of $X>5 .^{30}$

Our data do not show a correlation between a subject's average intrinsic value of decision rights and his or her loss aversion measure (pairwise correlation coefficient: $\rho=0.03 ; p=0.81$ ). Our data therefore do not lend support to the possibility that the measured difference in the certainty equivalents is mainly a manifestation of the subjects' loss aversion.

\subsection{Illusion of Control}

Illusion of control is a concept from psychology that goes back to Langer (1975). Charness and Gneezy (2010) defined illusion of control as being "concerned with greater confidence [...] in a favorable outcome when one has a higher degree of personal involvement, even when one's involvement is not actually relevant" (p. 134). To assess the behavioral relevance of the illusion of

\footnotetext{
${ }^{29}$ Each participant faces six lotteries that only affect his or her own payoff. After being presented with each lottery, the participant decides whether to accept it or not. Accepting involves a 50 percent chance of winning CHF 6 but a 50 percent chance of losing CHF $X$, where $X$ takes on the six different values $X \in\{2,3,4,5,6,7\}$ in the six different lotteries. If a participant rejects a given lottery, he receives a payoff of CHF 0 . Once all lottery decisions are taken, one of the six lotteries is randomly selected for actual payment and-in case of acceptance-a computerized random move determines the outcome. This design is adopted from Fehr and Götte (2007).

${ }^{30}$ In our data, all principals had a unique switching point. However, one principal rejected lotteries with low losses and accepted lotteries with high losses. Exclusion of this subject does not change the result.
} 
control, Charness and Gneezy (2010) elicited individuals' willingness to pay for personally rolling (instead of the experimenter rolling) a die that determined an individual's actual payment. They found that only a small minority of individuals (less than 10 percent) have a willingness to pay for rolling the die themselves in their task.

The findings of Charness and Gneezy (2010) cast doubt on the behavioral relevance of illusion of control. We nevertheless measured our subjects' illusion of control. The reason is that an illusion of control-if it existed-could have contributed to our main result because it could have increased the subjectively perceived instrumental value of the decision right.

We adopted a modified version of the incentive compatible elicitation method used by Charness and Gneezy (2010), and elicited each principal's willingness to pay for the right to personally roll the two ten-sided dice that determine the random outcomes in Part 1 and 2 of the experiment. ${ }^{31}$ If principals are subject to an illusion of control, they should value rolling the dice positively because this increases their personal involvement in determining the final outcomes: If a participant opts not to roll, the experimenter casts the dice in front of the participant. If the participant rolls the dice, the experimenter watches him or her do so. In both cases, the experimenter enters the result on the participant's computer screen.

In accordance with Charness and Gneezy (2010), we find that 91 percent of principals have no willingness to pay any amount for rolling the dice themselves. Hence, the correlation between the average individual intrinsic value of decision rights and the individual measure of control illusion is very low and even slightly negative (pairwise correlation coefficient: $\rho=-0.05$; $p=0.71)$.

\subsection{Preference Reversals}

It is a well-established result in experimental economics that preference reversals can occur when different procedures are used to elicit preferences over lotteries. Slovic and Lichtenstein (1968) first demonstrated this phenomenon;

\footnotetext{
${ }^{31}$ Recall that there are up to three random outcomes per participant, that is, the two ten-sided dice might have to be rolled up to three times. In Part 1 , the participant who ultimately holds the decision right can determine the success of the project by rolling the dice. In Part 2, two decisions are paid, that is, there are up to two lotteries with uncertain outcomes. The elicitation uses a Becker-DeGroot-Marschak mechanism where subjects could receive 30 points in return for giving up the right to roll the dice themselves (in the three cases mentioned above). Subjects stated how many of the 30 points they are willing to pay as a price for keeping the right to roll the dice themselves. They stated their willingness to pay before they knew whether they kept or received the decision right, and which lotteries were payoff relevant. The computer then drew the actual price from a uniform distribution over all integers from 1 to 30 including the bounds. If the actual price did not exceed the stated willingness to pay, a participant kept the right to roll the dice and received 30 points minus the actual price. If the actual price was higher, the subject received all 30 points and the experimenter rolled the dice.
} 
it received increased attention after a study by Grether and Plott (1979). They demonstrated that subjects valued some lottery A higher than a lottery B in a pricing task, but preferred lottery B over lottery A when faced with a binary choice between the two lotteries. These experiments usually involve a pair of lotteries with comparable expected value, but one lottery offers a high probability of winning a modest amount of money ("high-probability lottery"), whereas the other lottery offers a low probability of winning a large amount ("high-amount lottery"). Subjects tend to prefer the high-probability lottery when faced with a binary choice, but assign a higher value to the high-amount lottery in a pricing task. This phenomenon is shown to be due to overpricing of high-amount lotteries in the pricing task (Tversky, Slovic, and Kahneman (1990)).

Is it possible that the observed difference in certainty equivalents in Part 2 of our experiment stems from the phenomenon of overpricing high-amount lotteries (relative to high-probability lotteries)? More specifically, is it possible that subjects characterize the delegation lotteries they face in Part 2 as highamount lotteries and that they therefore place a higher certainty equivalent on these lotteries compared to the control lotteries?

The principals earn a higher amount in the delegation lottery in case of success than in the corresponding control lottery if $P_{\mathcal{P}}-C(E)$ is smaller than $P_{\mathcal{A}}$. It turns out, however, that there is no systematic relationship between the success payoff in the control lottery $\left(P_{\mathcal{P}}-C(E)\right)$ and the success payoff in the delegation lottery $\left(P_{\mathcal{A}}\right)$. In 49.5 percent of the cases, the control lottery's success payoff is larger, it is smaller in 49.5 of the cases, and the success payoffs are equal in 1 percent of the cases. There is thus no basis for characterizing the delegation lotteries as "high-amount lotteries." Moreover, our pairs of control and delegation lotteries also do not follow the high-probability versus highamount lottery pattern with respect to the probabilities of success. The average probabilities of success in the control and delegation lotteries are comparable; they amount to 60 percent in the control lotteries and to 51 percent in the delegation lotteries. In 49 percent of the lottery pairs, a higher probability of success is observed in the control lottery, while the probability of success is higher in the delegation lottery in 39.5 percent of the pairs. Eleven point five percent of the pairs have the same probability of success.

Finally, as shown in Section 4.1, we find consistent and significant differences not only in the certainty equivalents, but also in the expected values between the control and delegation lotteries. The principal's actions in Part 1 of the experiment determine these expected values, that is, the elicitation procedure in the lottery task of Part 2 cannot affect them. The overpricing of high-amount lotteries therefore cannot explain the differences in the expected values. It is exactly this overpricing, however, that underlies the preference reversal phenomenon. 


\subsection{Reciprocity}

Intention based reciprocity (e.g., Rabin (1993)) could, in principle, explain the measured difference in certainty equivalents in Part 2 of our experiment. To see this, consider the following argument: A negatively reciprocal principal chooses a low effort level $E$ that becomes relevant if she remains in control because she only keeps, by design, the decision right if the agent does not fulfill her minimum effort requirement. If the principal perceives the agent's effort choice as an "unkind act"-after all, it falls short of the minimum effort requirement-she may act in kind and choose a low effort level in order to lower the agent's expected payoff. The important consequence of this reciprocal reaction is that it reduces the principal's expected payoff in the control lottery relative to the delegation lottery. This in turn lowers the respective certainty equivalent, which could explain our main finding.

However, for the reciprocity argument to be valid, when the principal retains the decision right, her perception of the agent's unfriendliness should be higher, the lower the minimum effort requirement: If the agent does not even meet a very low requirement, the agent's effort level must be very "unkind." Hence, the differences in the certainty equivalents between the delegation and control lotteries in Part 2 should - according to the reciprocity argument-be higher, the lower the minimum effort requirement. It turns out that the opposite is true in our data. In a regression of the percentage difference in certainty equivalents on the minimum agent requirement, controlling for subject and game fixed effects, the percentage difference in the certainty equivalents increases by 4.5 percentage points per 10 point increase in the minimum agent requirement $(p<0.01$, standard errors clustered at the subject level). Thus, the data do not appear to be consistent with an explanation based on reciprocity.

\subsection{Failure to Elicit the Principal's Indifference Point}

The validity of our results depends on the correct elicitation of the indifference point in the delegation game. Hence, a potential concern is whether subjects understood the trade-off they faced in the delegation game, and whether we successfully elicited the indifference point. In particular, it could be that (i) violations of Assumption 3 (boundary condition) bias our main result or that (ii) subjects are boundedly rational and did not fully understand the elicitation mechanism.

\subsubsection{Corner Solutions}

We may fail to elicit a principal's point of indifference if she chooses a corner solution for $\underline{e}$ (see Assumption 3 and footnote 19). While principals rarely select $\underline{e}=100$ (1.9 percent) in our experiment, we observe a nonnegligible share of $\underline{e}=1$ choices (15.8 percent). If a principal chooses $\underline{e}=1$, Assumption 3 may 
be violated, that is, the utility derived from the control lottery $U\left(L^{c}, \omega=c\right)$ may be strictly smaller than the utility derived from the delegation lottery $U\left(L^{\underline{d}}(\underline{e}=1, \mathcal{A}), \omega=d\right)$. That is, a principal might even be willing to pay in order to delegate - on top of accepting a lottery in which an agent chooses $e=1$. In our experiment, however, we did not elicit such an additional willingness to pay for delegation. Our elicitation mechanism in Part 2 may thus fail to elicit the principal's point of indifference in these cases and, consequently, we may overestimate the average intrinsic value of decision rights.

We address this concern in several ways. First, most of our subjects never or rarely chose $\underline{e}=1$. Fifty-one percent of the subjects never chose $\underline{e}=1$ in our experiment, and $77 \%$ chose $\underline{e}=1$ twice at most. Therefore, for the majority of our subjects, violations of Assumption 3 only pose a minor problem that is unlikely to bias our results systematically. Second, we conducted a rather conservative version of the sign test for the null hypothesis that the median intrinsic value of decision rights is zero. The sign test is only based on data that indicate the sign but not the size of the intrinsic value measure. For our version of the sign test, we make the conservative assumption that principals who chose $\underline{e}=1$ value the decision right negatively (irrespective of the elicited certainty equivalents). We assign a positive intrinsic value to the decision right whenever the principal chose $\underline{e}>1$ and the corresponding certainty equivalent of the delegation lottery is larger than the certainty equivalent of the control lottery. We can then calculate how often each principal assigns a positive or negative intrinsic value in the ten games. We find that the number of principals who have a positive intrinsic value more often (49) is significantly larger, at the $1 \%$ significance level, than the number of subjects who have a negative intrinsic value more often (14). ${ }^{32}$ We also conducted a sign test for each of the ten games separately, and find that principals significantly more often have a positive intrinsic value in 8 out of the 10 games with at least $5 \%$ significance. We only fail to find a significant difference in games 5 and 9 .

Third, we directly addressed the question whether those principals who choose $\underline{e}=1$ indeed have a willingness to pay for delegation by conducting an additional control experiment with 34 subjects. Part A of this experiment was equivalent to Part 1 of our main treatment. It served the purpose of identifying principals who choose $\underline{e}=1$ and the games in which they do so. In Part B of the control experiment, we measured whether these principals are willing to pay for delegation. Part B was identical to Part A except for the following changes: (i) It was common knowledge that the agents always had to choose an effort of $e=1$ and project alternative $\mathcal{A}$ in case of delegation, and that the principals might have to pay in order to delegate. (ii) Instead of announcing a minimum effort requirement as in Part A, the principals explicitly stated whether they wanted to keep control or delegate. (iii) If a principal kept control, she had to

\footnotetext{
${ }^{32}$ For the remaining subjects, the number of games in which the measured intrinsic value was positive or negative is equal.
} 
choose her implementation effort and the project alternative. But if a principal preferred delegation, we explicitly asked her to state her willingness to pay for delegation. The actual cost of delegation was drawn from a uniform distribution between 0 and 100 points. If the stated willingness to pay for delegation was above the realized cost, the principal paid that actual cost and delegated the decision right. Otherwise, the principal kept the decision right and her chosen project alternative and effort were implemented. This procedure ensured that a principal had an incentive to state her true willingness to pay for delegation. This willingness to pay for delegation informs us about the extent to which we may overestimate the intrinsic value of decision rights when corner solutions are chosen.

The principals chose the corner solution $\underline{e}=1$ in 31 (18 percent) of 170 cases in Part A, but they were not willing to pay anything for delegating in Part B in 30 out of these 31 cases. The control experiment thus shows that those principals who choose a minimum effort requirement of 1 almost never have a positive willingness to pay for delegation. We therefore conclude that our measure of the intrinsic value of decision rights is very unlikely to be distorted by those principals who choose $\underline{e}=1$.

\subsubsection{Bounded Rationality}

While it is not clear that a possible confusion on the part of the subjects would lead to a systematically higher valuation of the delegation over the control lotteries in Part 2, and not simply to more noise, we consider it important to highlight the measures that we took to ensure a clear understanding of the experimental conditions.

First, subjects received comprehensive and detailed instructions in which the trade-off between keeping and delegating the decision right was explained. They also had to answer detailed control questions correctly before they were allowed to participate in the experiment. In particular, principals were explicitly instructed to think about their point of indifference when choosing the minimum effort requirement: They were told to consider that the agent chooses some effort $e$, and to decide whether they would be willing to delegate the decision right to the agent if he chooses precisely this effort level. If they prefer keeping the decision right in this case, they were instructed to repeat the exercise assuming that the agent chooses an effort of $e+1$. It was then explained to them that they should set the minimum requirement exactly at agent's lowest effort level at which they prefer delegation. Hence, principals were instructed in a way that should lead them to reveal their point of indifference..$^{33}$

\footnotetext{
${ }^{33}$ To avoid anchoring the principals to high effort values, the numerical example in the instructions started with an agent effort of 1 . Consequently, if anchoring is a concern, it would work against our hypothesis, since it would create delegation lotteries of low value.
} 
Second, principals were given the possibility of revising their choices during the experiment. After having chosen the minimum effort requirement and their own effort in case they retain the decision right, principals were shown the consequences of these choices side-by-side on their computer screen.$^{34}$ In particular, they were shown the consequences of delegation assuming that the agent chooses precisely the minimum requirement (and project alternative $\mathcal{A}$ ), that is, the worst possible outcome after delegation, and the consequences of keeping the decision right (given their own effort and choice of the alternative). Note that these are precisely the outcomes that define the control and the delegation lotteries. At this stage, principals had the possibility of revising all their choices, that is, they could change the minimum requirement or the own effort choice if they wished to do so. This design feature allowed them to fine-tune their choices in the delegation game in order to facilitate the revelation of the point of indifference.

Further, the data indicate that the principals understood the trade-offs they faced when setting the minimum effort requirement well. In Table I, we present predicted values for the minimum requirement assuming that principals are risk neutral and purely self-interested, and do not derive intrinsic value from the decision right. While we should not expect the observed values to co-vary perfectly with these predictions, they are a useful benchmark for the variation in the actual minimum requirements across games. A regression of the chosen minimum effort requirements on the predicted values for $\underline{e}$ in Table I confirms that the requirements vary as expected. The coefficient on the predictions is $0.74(p<0.01)$, that is, if the prediction increases by 1 point, the actually chosen minimum effort requirement increases by 0.74 points. ${ }^{35}$ Hence, the principals react strongly and in the predicted direction to changes in the delegation trade-off, which is further evidence that our subjects understood the experimental conditions well. ${ }^{36}$

\footnotetext{
${ }^{34} \mathrm{An}$ English translation of the instructions to the principal can be found on p. 2 of the Supplemental Material, and the screenshots of the principals' screen sequence in the delegation game can be found on p. 15 of the Supplemental Material.

${ }^{35}$ Standard errors in the regression are clustered on the subject level.

${ }^{36}$ One specific form of bounded rationality would be to assume that principals form expectations about others' behaviors in the lab or in real life by analogy with more familiar setups in which they know more about the effect of their actions on others (Samuelson (2001), Jehiel (2005)). It could then be that principals expect their agents to shirk strongly after delegation, and this could induce principals to set suboptimally high minimum effort requirements to avoid that delegation occurs. Note, however, we must assume that the subjects fundamentally misunderstood the delegation mechanism in our experiment for this explanation to be valid because the principal's beliefs about the agent's effort are completely irrelevant for the optimal choice of the minimum effort requirement. Keep in mind that subjects were only allowed to participate in the experiment if they correctly answered all control questions. In addition, as described above, we devoted much effort in the instructions to explain the logic of setting an optimal minimum effort requirement.
} 


\section{CONCLUSION}

In this paper, we provide evidence that individuals value decision rights intrinsically, demonstrate the robustness of this finding across different game parameterizations, and find that the magnitude of the intrinsic value of decision rights is correlated across individuals and parameterizations. These results provide evidence for the existence of non-transferable private benefits of control, the implications of which have been studied intensively in the theoretical corporate finance, governance, and organizational economics literatures. Evidence for the existence of such "psychic" private benefits makes a strong case for the relevance of the incomplete contracting approach in these literatures.

What determines the size of the intrinsic value of decision rights? In this paper, we can only provide preliminary answers to the situational determinants of intrinsic value. We find that stake size matters. Doubling the stake size involved in a decision roughly doubles the intrinsic value component. With regard to the conflict of interest between the principal and the agent, a first intuition might suggest that the intrinsic value of decision rights is larger, the larger the conflict of interest. If their interests are perfectly aligned, for example, having the decision right might not be intrinsically valuable since the power relationship is less pronounced. Our data, however, point in the opposite direction. Our interpretation is that decisions where the pursuit of self-interest runs counter to the interests of another party have an "unpleasant" component attached to them, which reduces the intrinsic value of decision rights. This effect might go so far that the intrinsic value of decision rights may even turn negative in situations with undesirable outcomes. This would be consistent with recent experimental findings on the attribution of responsibility for unfair decisions (Bartling and Fischbacher (2012)). We consider gaining further insights into the situational determinants of the intrinsic value of decision rights to be an interesting field for future research.

The finding that individuals intrinsically value decision rights naturally leads to the question of the ultimate reason why people value decision rights beyond their instrumental benefits. One potential source stems directly from having or not having decision rights. Social psychologists argue that "human needs," such as power (McClelland (1975)) or autonomy (Deci and Ryan (1985)) constitute the source of the intrinsic value of power and autonomy. While the need for power implies that individuals value decision rights positively, the need for autonomy is potentially based on an aversion against being subordinate. Alternatively, decision rights could be intrinsically valuable because the utility received from specific outcomes depends on whether the outcome is a consequence of one's own actions, the actions of someone else, or not the consequence of a choice at all. For example, Nozick (1974, pp. 48-51) argued that a person who shapes his own life according to his own plan gives meaning to that life. Hence, the same outcome may be more valuable if it is self-chosen rather 
than imposed by someone else ${ }^{37}$ Further exploring these potential sources of the intrinsic value of decision rights provides exciting avenues for future research.

\section{REFERENCES}

AGHION, P., AND P. BOLTON (1992): "An Incomplete Contracts Approach to Financial Contracting," Review of Economic Studies, 59 (3), 473-494. [2008]

AGHION, P., AND J. TIROLE (1997): "Formal and Real Authority in Organizations," Journal of Political Economy, 105 (1), 1-29. [2005,2009]

BARTLING, B., AND U. FISCHBACHER (2012): "Shifting the Blame: On Delegation and Responsibility," Review of Economic Studies, 79 (1), 67-87. [2008,2036]

BARTLING, B., E. FEHR, AND H. HERZ (2014): "Supplement to 'The Intrinsic Value of Decision Rights'," Econometrica Supplemental Material, 82, http://dx.doi.org/10.3982/ECTA11573. [2017]

BARTLING, B., E. FEHR, AND K. M. SCHMIDT (2012): "Screening, Competition, and Job Design: Economic Origins of Good Jobs," American Economic Review, 102 (2), 834-864. [2009] (2013): "Use and Abuse of Authority: A Behavioral Foundation of the Employment Relation," Journal of the European Economic Association, 11 (4), 711-742. [2005]

BECKER, G. M., M. H. DEGroOt, AND J. MARSChAK (1964): "Measuring Utility by a SingleResponse Sequential Method," Behavioral Science, 9, 226-232. [2015]

CHARNESS, G., AND U. GNEeZY (2010): "Portfolio Choice and Risk Attitudes: An Experiment," Economic Inquiry, 48 (1), 133-146. [2029,2030]

Christman, J. (2011): "Autonomy in Moral and Political Philosophy," in The Stanford Encyclopedia of Philosophy, ed. by N. Zalta. Available at http://plato.stanford.edu/archives/spr2011/ entries/autonomy-moral/. [2006]

CRONBACH, L. J. (1951): "Coefficient Alpha and the Internal Structure of the Tests," Psychometrika, 16, 297-334. [2026]

DAHL, R. (1957): “The Concept of Power," Behavioral Science, 2, 201-215. [2028]

DECI, E. L., AND R. M. RYAN (1985): Intrinsic Motivation and Self-Determination in Human Behavior. New York: Plenum. [2006,2036]

(2000): "The 'What' and 'Why' of Goal Pursuits: Human Needs and the SelfDetermination of Behavior," Psychological Inquiry, 11 (4), 227-268. [2006]

DESSEIN, W. (2002): "Authority and Communication in Organizations," Review of Economic Studies, 69 (4), 811-838. [2005]

DomingueZ-MarTineZ, S., R. SLOOF, AND F. von SIEMENS (2014): "Monitored by Your Friends, not Your Foes: Strategic Ignorance and the Delegation of Real Authority," Games and Economic Behavior, 85, 289-305. [2009]

${ }^{37}$ Mill (1859, Chapter III) put forward a similar argument in his defense of liberty: "He who lets the world, or his own portion of it, choose his plan of life for him, has no need of any other faculty than the ape-like one of imitation. He who chooses his plan for himself, employs all his faculties. He must use observation to see, reasoning and judgment to foresee, activity to gather materials for decision, discrimination to decide, and when he has decided, firmness and self-control to hold to his deliberate decision. And these qualities he requires and exercises exactly in proportion as the part of his conduct which he determines according to his own judgment and feelings is a large one. It is possible that he might be guided in some good path, and kept out of harm's way, without any of these things. But what will be his comparative worth as a human being? It really is of importance, not only what men do, but also what manner of men they are that do it." 
DYCK, A., AND L. ZINGALES (2004): "Private Benefits of Control: An International Comparison," Journal of Finance, 59 (2), 537-600. [2008]

FALK, A., AND M. KosfelD (2006): “The Hidden Costs of Control," American Economic Review, 96, 1611-1630. [2009]

FEHR, E., AND L. GOETTE (2007): "Do Workers Work More if Wages Are High? Evidence From a Randomized Field Experiment," American Economic Review, 97 (1), 298-317. [2029]

FEHR, E., H. HERZ, AND T. WILKENING (2013): "The Lure of Authority: Motivation and Incentive Effects of Power," American Economic Review, 103 (4), 1325-1359. [2009]

FISCHBACHER, U. (2007): “z-Tree: Zurich Toolbox for Ready-Made Economic Experiments," $E x$ perimental Economics, 10 (2), 171-178. [2017]

FREY, B. S., M. BENZ, AND A. STUTZER (2004): “Introducing Procedural Utility: Not Only What, but Also how Matters," Journal of Institutional and Theoretical Economics, 160 (3), 377-401. [2006]

GrEINER, B. (2004): "An Online Recruitment System for Economic Experiments," in Forschung und wissenschaftiches Rechnen. Göttingen: GWD. [2017]

GRETHER, D. M., AND C. R. PlotT (1979): "Economic Theory of Choice and the Preference Reversal Phenomenon," American Economic Review, 69 (4), 623-638. [2031]

Grossman, S., AND O. HART (1986): "The Costs and Benefits of Ownership: A Theory of Vertical and Lateral Integration," Journal of Political Economy, 94 (4), 691-719. [2005]

HAMILTON, B. H. (2000): "Does Entrepreneurship Pay? An Empirical Analysis of the Returns to Self-Employment," Journal of Political Economy, 108 (3), 604-631. [2008]

HANDEL, M., AND D. LEVINE (2004): "The Effects of New Work Practices on Workers," Industrial Relations, 43 (1), 1-43. [2009]

HART, O., AND J. MOORE (1990): "Property Rights and the Nature of the Firm," Journal of Political Economy, 98 (6), 1119-1158. [2005]

- (1995): "Debt and Seniority: An Analysis of the Role of Hard Claims in Constraining Management," American Economic Review, 85 (3), 567-585. [2008]

HERZ, H. (2011): "Essays in Organizational and Personnel Economics," Ph.D. Thesis, University of Zurich. [2025]

ICHNIOWSKI, C., AND K. SHAW (2003): “Beyond Incentive Pay: Insiders' Estimates of the Value of Complementary Human Resource Management Practices," Journal of Economic Perspectives, 17 (1), 155-180. [2009]

ICHNIOWSKI, C., K. SHAW, AND G. PRENNUSHI (1997): "The Effects of Human Resource Practices on Manufacturing Performance: A Study of Steel Finishing Lines," American Economic Review, 87 (3), 291-313. [2009]

JEHIEL, P. (2005): "Analogy-Based Expectation Equilibrium," Journal of Economic Theory, 123 (2), 81-104. [2035]

JENSEN, M., AND W. MECKLING (1976): "Theory of the Firm: Managerial Behavior, Agency Costs and Ownership Structure," Journal of Financial Economics, 3, 305-360. [2008]

KAHNEMAN, D., AND A. TVERSKY (1979): "Prospect Theory: An Analysis of Decision Under Risk," Econometrica, 47 (2), 263-291. [2029]

LANGER, E. J. (1975): “The Illusion of Control," Journal of Personality and Social Psychology, 32 (2), 311-328. [2029]

LOCKE, J. (1975[1690]): An Essay Concerning Human Understanding, ed. by P. H. Nidditch. Oxford: Clarendon Press. [2028]

LUKES, S. (2005): Power: A Radical View (Second Ed.). Basingstoke: Palgrave MacMillan. [2028]

MCClelland, D. C. (1975): Power: The Inner Experience. Irvington, NY: Halsted Press. [2006, 2036]

MiLL, J. S. (1991[1859]): On Liberty. Oxford: Oxford University Press. [2006,2010,2037]

Morrow, D. J. (1998): "A Tale of Executives and Egos: When Does the Board Decide It's Time to Tell a Chief He Must Leave?" New York Times, October 23, p. C6. [2008]

MOSKOWITZ, T. J., AND A. VISSING-JøRGENSEN (2002): “The Returns to Entrepreneurial Investment: A Private Equity Premium Puzzle?” American Economic Review, 92 (4), 745-778. [2009] 
NiSKANEN, W. A. (1971): Bureaucracy and Representative Government. Chicago: Aldine-Atherton. [2009]

NOZICK, R. (1974): Anarchy, State and Utopia. Oxford: Basil Blackwell. [2036]

Nussbaum, M. C. (2000): Women and Human Development: The Capabilities Approach. Cambridge: Cambridge University Press. [2006,2010]

OSTERMAN, P. (2006): "The Wage Effects of High Performance Work Organization in Manufacturing," Industrial and Labor Relations Review, 59 (2), 187-204. [2009]

OWENS, D., Z. GROSSMAN, AND R. FACKLER (2014): "The Control Premium: A Preference for Payoff Autonomy," American Economic Journal: Microeconomics, 6 (4), 138-161. [2009]

PolsBY, N. W. (1963): Community Power and Political Theory. New Haven, CT: Yale University Press. [2028]

Pugsley, B. W. AND E. HuRSt (2011): "What Do Small Businesses Do?" Brookings Papers on Economic Activity, 43 (2), 73-142. [2009]

PUPPE, C. (1996): “An Axiomatic Approach to 'Preference for Freedom of Choice'," Journal of Economic Theory, 68, 174-199. [2010]

RABIN, M. (1993): "Incorporating Fairness Into Game Theory and Economics," American Economic Review, 83 (5), 1281-1302. [2032]

SAMUELSON, L. (2001): “Analogies, Adaptation, and Anomalies," Journal of Economic Theory, 97 (2), 320-366. [2035]

SEN, A. (1985): Commodities and Capabilities. Oxford: Oxford University Press. [2006,2010]

SimON, H. (1951): "A Formal Theory of the Employment Relation," Econometrica, 19 (3), 293-305. [2005]

SLOVIC, P., AND S. LichtensteIN (1968): "Relative Importance of Probabilities and Payoffs in Risk Taking," Journal of Experimental Psychology, 78 (3), 1-18. [2030]

SMITH, A. (1978): Lectures on Jurisprudence (1762/63). Oxford: Oxford University Press. [2006]

STERN, S. (2004): "Do Scientists Pay to Be Scientists," Management Science, 50 (5), 835-853. [2008]

TVERSKY, A., P. Slovic, AND D. KAHNEMAN (1990): "The Causes of Preference Reversals," American Economic Review, 80, 204-217. [2031]

Dept. of Economics, University of Zurich, Blümlisalpstrasse 10, CH-8006 Zurich, Switzerland; bjoern.bartling@econ.uzh.ch,

Dept. of Economics, University of Zurich, Blümlisalpstrasse 10, CH-8006 Zurich, Switzerland; ernst.fehr@econ.uzh.ch,

$$
\text { and }
$$

Dept. of Economics, University of Zurich, Blümlisalpstrasse 10, CH-8006 Zurich,Switzerland; holger.herz@econ.uzh.ch.

Manuscript received April, 2013; final revision received July, 2014. 